\title{
Ceramic Foam Catalyst Substrates for Diesel Oxidation Catalysts: Pollutant Conversion and Operational Issues
}

\author{
Christian Bach and Panayotis Dimopoulos Eggenschwiler \\ EMPA
}

\begin{abstract}
In the field of automotive exhaust catalysts, foam-type substrates have been proposed as alternatives to the wellestablished honeycomb substrates. The ceramic foams developed and manufactured in our laboratory are capable of redistributing the flow of exhaust gases, enhancing turbulence, mass transfer and species mixing, without increasing flow resistance and pressure drop to prohibitive levels. Based on the characteristics of turbulent mass and heat transfer, ceramic foam based catalysts have the potential for achieving similar pollutant conversion performances as state of art honeycomb catalysts with substantially lower precious metal requirements.
\end{abstract}

In this paper we demonstrate this potential with a small Diesel powered Heavy Duty truck with a ceramic foam Diesel Oxidation Catalyst (DOC). Given the substantial differences in geometrical properties between foams and honeycombs a direct comparison with equal coating thickness, amount and precious metal amount is not feasible. We present however systematic comparisons with known precious metal amounts while pointing out important differences in the wash coating characteristics. As strongly affected, crucial operational characteristics we comment on, are the pressure drop and the homogenizing properties of the substrates on the temperature distribution.

For the DOC applications we compared catalysts with an overall volume ratio of $1.4: 1$ (honeycomb:foam). The comparisons involved the serial production honeycomb to specifically coated foams. Here the wash coat amounts have been chosen in order to achieve almost equal layer thicknesses (wash-coat amount ratio of 6.5:1, honeycomb:foam). The entire precious metal load on the foam was approx. 2.8 times less than the corresponding one on the compared honeycomb.

The conversion performances achieved with the foam catalyst were almost equal to those achieved by the honeycomb in respect to $\mathrm{CO}$ and $\mathrm{THC}$ oxidation, although honeycombs had 2.8 times more precious metals. In addition, the foams exhibited substantially better particle oxidizing behavior, as particle number measurements have shown. Nevertheless, NO oxidation light-off performance of the foams was worse. This may be attributed to different wash coat compositions, the wash coat composition of the serial production honeycomb was not fully known. The comparison of two differently coated foam DOCs have given insights in the conversion dependencies on the coating parameters and have shown further optimization directions.

\section{INTRODUCTION}

In the field of automotive exhaust catalysts, foam-type substrates have been proposed, as alternatives to the wellestablished honeycomb substrates. These applications involve the use of foams as Diesel Particulate Filters (DPF) or combined Diesel Oxidation Catalysts (DOC) and DPF systems $[\underline{1}, \underline{2}, \underline{3}]$. Initial investigations of the application of ceramic foams as substrates for 3-Way Catalytic Converters (TWC) for natural gas engines have been performed in our laboratory. The results showed similar chemical activity of ceramic foams and honeycomb monoliths at varying air-tofuel ratios [4]. Moreover, the pollutant conversion achieved with ceramic foam substrates during engine tests at representative operating points was at least as high as the one achieved with a conventional honeycomb monolith []ㅡ. 
Exhaust flow uniformity in catalytic converters plays an important role, particularly under high exhaust gas velocities. Several studies report that flow non-uniformity has a negative impact on pollutant conversion efficiency and on catalyst durability $[\underline{6}, 7]$. In modern exhaust aftertreatment systems, where different exhaust aftertreatment devices are used in a cascade configuration, the flow uniformity downstream of each substrate affects the performance of aftertreatment devices located further downstream. Such is the case of DPFs, which are typically located directly downstream of DOCs. The flow uniformity at the DPF entrance is expected to strongly affect the soot deposition uniformity. [ $\underline{8}]$ identified uniform soot deposition as a key factor for a reliable DPF system As a means to achieve uniform flow distribution upstream of DPFs the use different types of flow elements have been proposed, [9].

Pressure drop is an important property of catalytic substrates, as it affects the engine fuel consumption. The pressure drop per unit length of ceramic foams is known to be higher, compared to honeycomb monoliths. This, however, can be partly compensated, either by downsizing the ceramic foam substrate, which is made possible by the increased mass transfer of foams compared to honeycomb monoliths [10], or by using radial-flow foam substrates [1], which involve smaller length for the same substrate volume.

Following a systematic development process, our laboratory has extensively investigated material issues, [11], the fluid dynamic behavior, $[\underline{12}, \underline{13}]$, reactivity in the exhaust gas of natural gas engines [ $4, \underline{5}]$, while using simulation for analyzing the underlying phenomena, [14]. In this study the focus was the realization of a foam based DOC for a small heavy duty truck. The comparison to the original honeycomb based catalyst was one major issue. Apart from that the thermal homogenization impact of the catalysts systems and the flow resistance have been compared.

\section{EXPERIMENTAL SETUP AND VEHICLE OPERATIONAL CHARACTERISTICS}

\section{VEHICLE, TEST BENCH AND ANALYSIS EQUIPMENT}

The tests have been performed on a chassis dynamometer as can be seen in Fig. 1. The vehicle used for the experiments is an Iveco Daily, a small heavy duty truck, equipped with a 2.3-litre 4 cylinder (F1A) common rail diesel with turbocharger. In place of the original DOC-DPF system a specially manufactured DOC-DPF casing was used in order to enable easy exchanges, Fig. 2 . The casing was positioned approx. $0.5 \mathrm{~m}$ further apart from the engine in respect to the original aftertreatment system position. The inlet to the casing was placed slightly eccentrical with a $45^{\circ}$ bend (Fig.
2). Three measurement interfaces have been defined and instrumented: Measurement plane A positioned upstream of the DOC was used for measuring raw engine emissions. Measurement plane B downstream the DOC, and thus upstream of the DPF, and measurement plane $\mathrm{C}$ downstream the DPF have been extensively used. As a DPF the original honeycomb based Daily DPF was used. For isolating the performance of the DOCs to be compared, from any influence of the DPF downstream, most results presented in this work have been measured with the casing as shown in Fig. 2 but without a DPF.

In all relevant measurement planes gas pressure, gas temperature, and species concentrations $\left(\mathrm{CO}_{2}, \mathrm{O}_{2}, \mathrm{NO}, \mathrm{NO}_{\mathrm{x}}\right.$, $\mathrm{CO}, \mathrm{THC})$, as well as particle number have been measured. Available were NDIR analyzers (for $\mathrm{CO}_{2}$ and $\mathrm{CO}$ ), FIDs for the total unburnt hydrocarbons (THCs), as well as CLDs for $\mathrm{NO}_{\mathrm{x}}$ and $\mathrm{NO}$. Apart from the $\mathrm{NO}_{\mathrm{x}}$ and $\mathrm{NO}$ all other exhaust species have been measured simultaneously in the 3 relevant measurement planes. NO has been measured simultaneously pre and post DOC, together with engine-out pre $\mathrm{DOC} \mathrm{NO}_{\mathrm{x}}$. We assumed that the overall $\mathrm{NO}_{\mathrm{x}}$ change over the DOC is marginal. This assumption was confirmed in further measurement series.

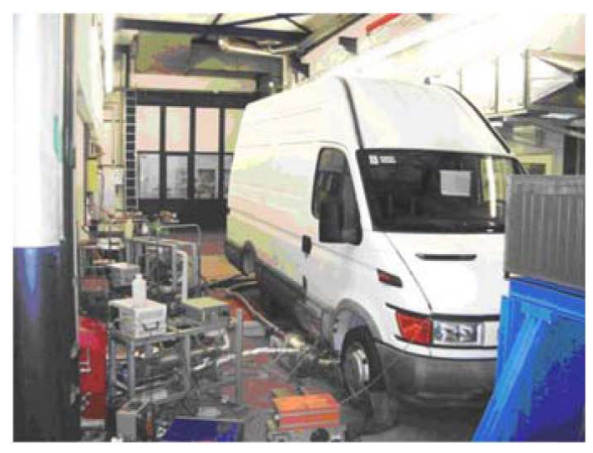

Figure 1. Small heavy duty truck on the chassis dynamometer

Particle number was measured also simultaneously pre and post DOC by Condensation Particle Counters (CPCs) using the appropriate dilution. For the particle measuring techniques implemented in this study the interested reader is referred to [15].

Temperature measurement has been conducted using 3 thermocouples in every measurement plane. One of those was measuring the temperature in the center of the aftertreatment cross section, while the other two were located (in the exhaust gas stream) but in the periphery.

All analyzers and measuring systems have been sampled with $1 \mathrm{~Hz}$. 


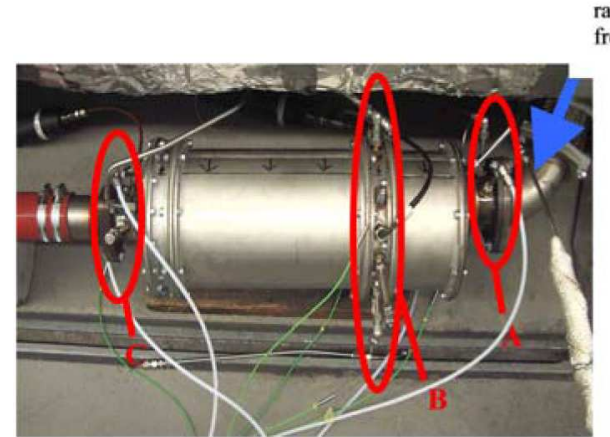

Figure 2. Aftertreatment system and instrumentation

\section{INVESTIGATED ENGINE OPERATING DOMAIN}

For investigating a broad domain of engine and exhaust gas conditions, the approach chosen on the chassis dynamometer was a constant velocity of approx. $70 \mathrm{~km} / \mathrm{h}$ and variable loads. The force measurement on the dyno is the most reliable quantification for the engine output.

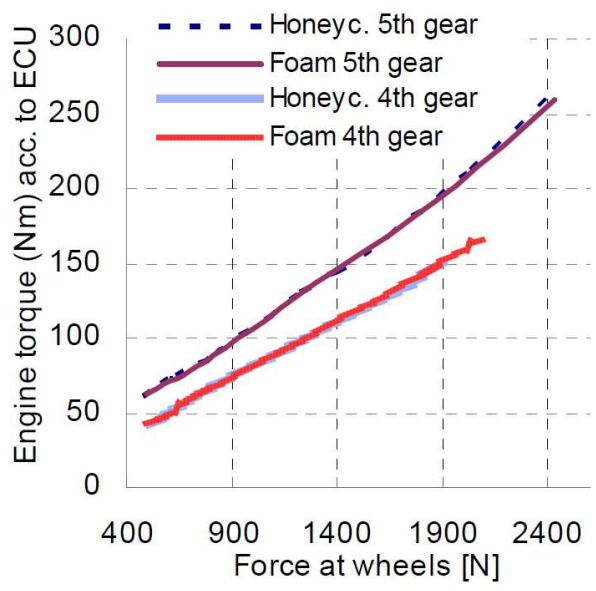

Figure 3. Force at the chassis dyno as a function of the engine torque in the examined engine operating points

For the comparison of the performance of the different catalysts we chose the operating points associated with the two higher gears of the gearbox (the $4^{\text {th }}$ and the $5^{\text {th }}$ gear) allowing the investigation of the catalysts' behavior over a broad domain of engine operating points, engine raw emissions, exhaust temperatures and exhaust mass flows (a broad domain of gas hourly space velocities through the catalysts). Fig. 3 shows the engine torque as given by the ECU of the engine as a function of the output at the wheels as measured by the chassis dyno. The corresponding exhaust gas temperatures upstream the DOCs are shown in Fig. 4. Apart from showing major characteristics of the engine operation test points, Figs. 3 and $\underline{4}$ document the almost identical engine operating conditions the catalysts have been tested at.

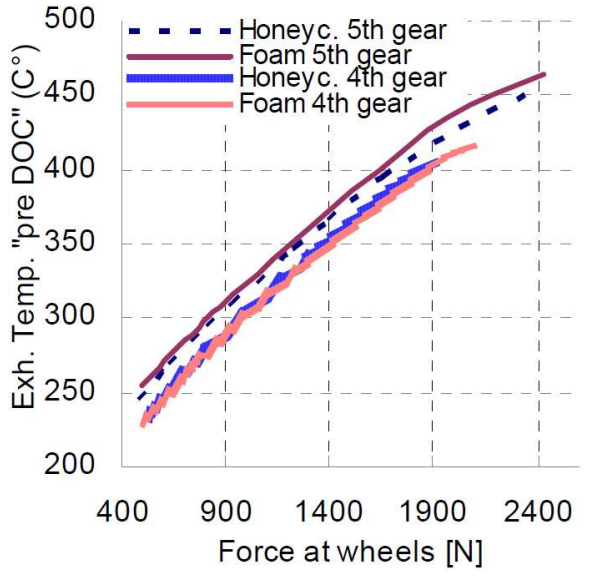

Figure 4. Exhaust gas temperature in the examined engine operating points

\section{COMPARED CATALYSTS}

The honeycombs used for the measurements and the comparisons with foams have been the original Iveco Daily DOCs. Composed out of cordierite they feature a $400 \mathrm{cpsi}$ channel density with $6.5 \mathrm{mil}$ thick walls. The outer dimensions have been approx. $170 \mathrm{~mm}$ (6.66inch) diameter, and $101 \mathrm{~mm}$ (4 inch) length leading to an overall volume of $2306 \mathrm{~cm}^{3}$. The specific surface of such a structure lies at $2.740 \mathrm{~m}^{2} / \mathrm{lt}$. The platinum density of $100 \mathrm{~g} / \mathrm{ft}^{3}$, resulted in overall $8.144 \mathrm{~g}$ of $\mathrm{Pt}$ in the entire catalyst. The remaining characteristics of the coating could only be roughly estimated. Based on SEM images the mean wash coat thickness could be estimated at $0.030 \mathrm{~mm}$ (typical value for such catalysts).

The foams have been in-house manufactured based on antecedent development, $[11,12]$. Composed out of $\mathrm{A}_{2} \mathrm{O}_{3}$ the chosen foams had a porosity of 10ppi. Interpretation of the catalytic activity requires some knowledge of the geometrical features of the foams. Therefore the foams were modeled as stacked void Kelvin cells comprising of cylindrical struts on the Kelvin cell edges. Based on this assumption, often used in modeling of porous media such as foams $[\underline{10}, \underline{16}, \underline{17}, \underline{18}]$, the geometric model was build $[\underline{4}, \underline{5}]$. According to the model the used 10ppi foams with approx. $90 \%$ porosity had an average pore diameter of $2.54 \mathrm{~mm}$. The average strut had a diameter of $0.32 \mathrm{~mm}$ and a length of $0.91 \mathrm{~mm}$. The specific surface area (SSA) was computed accordingly to be $1.266 \mathrm{~m}^{2} / \mathrm{lt}$, thus roughly 2.2 times lower than the specific surface area of the honeycombs.

Ideally, a catalyst substrate comparison in terms of reactivity should involve substrates with the same wash coat amount, the same platinum group metal (PGM) quantity as well as the same available surface area for reactions (equal temperatures in the upstream as well as at equal gas compositions, as 
discussed in the previous subsection are also essential). It is obvious that the difference in the specific surface area of the investigated substrates does not allow such a direct comparison. Should the amount of wash coat be kept equal, ceramic foams will feature a 2.2 times thicker coating layer. The relative slow diffusion, [19], in the tortuous wash coat renders thick layers useless underestimating the catalytic performance if expressed in relation to the amount of the used catalytic materials. Therefore it was decided to compare substrates with approx. the same average wash coat thickness. This had some implications for the coating process since the layer thickness cannot be directly controlled. Merely the required coating weight can be targeted and only after the coating process is accomplished, the effective weight of the adhered coating material on the substrate can be determined. In a next step, using the specific surface area of the substrate based on the geometric model, an average wash coat thickness can be computed. In addition, the Pt amount has to be adjusted during the coating preparation in order to achieve the targeted PGM density on the substrate volume. This introduced additional complications since precious metal density variation possibilities in the wash coat are also limited. Apart form that, the main aspiration for the present work was the demonstration of ceramic foam based catalysts with low Pt loading and small overall volume leading to comparable catalytic activities as conventional honeycombs with higher Pt amount and bigger dimensions.

Catalytic coating of the foams was performed by Umicore Automotive Catalysts AG. Compliance with all the requirements discussed above as well as the coating process requirements led to catalysts according to Table 1 . All the comparisons presented in the results and discussion section involve the honeycomb in respect to Foam 1. Comparisons between the two different foams are also presented in order to assess the effect of the different coatings and dimensions.

Table 1. Main characteristics of the compared catalysts

\begin{tabular}{|l|l|l|l|}
\hline & Honeycomb & Foam 1 & Foam 2 \\
\hline $\mathrm{D}[\mathrm{mm}]$ & 170 & 170 & 170 \\
\hline $\mathrm{L}[\mathrm{mm}]$ & 101.6 & 72 & 54 \\
\hline $\mathrm{V}\left[\mathrm{cm}^{3}\right]$ & 2306 & 1634 & 1225 \\
\hline $\mathrm{SSA}\left[\mathrm{m}^{2} / \mathrm{lt}\right]$ & 2.740 & 1.266 & 1.266 \\
\hline Avail. Reaction surf. $\left[\mathrm{m}^{2}\right]$ & 6.3199 & 2.069 & 1.5517 \\
\hline Pt content (rel.) $\left[\mathrm{g} / \mathrm{ft}^{3}\right]$ & 100 & 50 & 100 \\
\hline Pt content $($ abs) $[\mathrm{g}]$ & 8.144 & 2.8857 & 4.3285 \\
\hline Aver. wash coat thickn. $[\mathrm{mm}]$ & 0.03 & 0.026 & 0.048 \\
\hline
\end{tabular}

A selection of the coated foams was further examined in order to asses the geometric model as well as whether the targeted average wash coat thickness was achieved. Fig. 5 shows a SEM exposure of the cross section of one typical strut. The coating layer is easy to discern. The thickness of the layer is not uniform and amounts from 42 to $8 \mu \mathrm{m}$ having an average of roughly $26 \mu \mathrm{m}$. Based on the weight increase of the foam over the coating process and a series of such SEM image evaluations the geometric model could be confirmed.

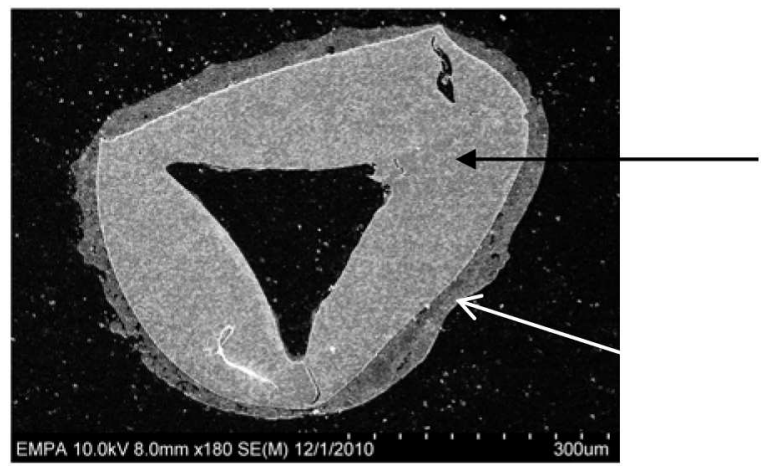

Figure 5. Cross section of the strut of the foam in the SEM

An additional notice for caution is necessary. Were the precious metal contents of the confronted catalysts known, the wash coat composition of the original honeycomb in respect to other components was unknown. Thus some behavior differences may be attributable to different wash coat constituents and compositions. The wash coat for the foams has been a monolayer with uniform distribution of the different components over its cross section. This is rather unlikely to be the case in the original honeycomb. Serial production catalysts have in their vast majority a multilayer design.

\section{RESULTS AND DISCUSSION}

\section{OPERATION: PRESSURE DROP AND THERMAL HOMOGENIZATION OF EXHAUST}

Fig. 6 shows the pressure drop over the DOCs in comparison at the engine operating points as described in the former section. The DPF was removed from the exhaust aftertreatment casing, Fig. 2, in order to assess only the effect of the substrates of the DOCs and to remove the influence of different DPF soot load. However, an additional flow resistance in form of an orifice had to be positioned in the downstream of the DOCs in order to mimic the higher pressure drop of the exhaust aftertreatment system for the engine control unit (ECU). Thus the pressure drop values in Fig. 6 are too high and representative for the operation with a DPF. Nevertheless, all DOC $\mathrm{s}$ have been tested under the identical conditions. As can be seen in Fig 6 the pressure drop of the compared substrates are almost equal, the honeycomb always leading to slightly higher pressure drop. It should be kept in mind, that the entire honeycomb volume was 1.4 times bigger in respect to that of the foam (Table 1), a fact that can, at least partly [13], explain the higher pressure drop. 


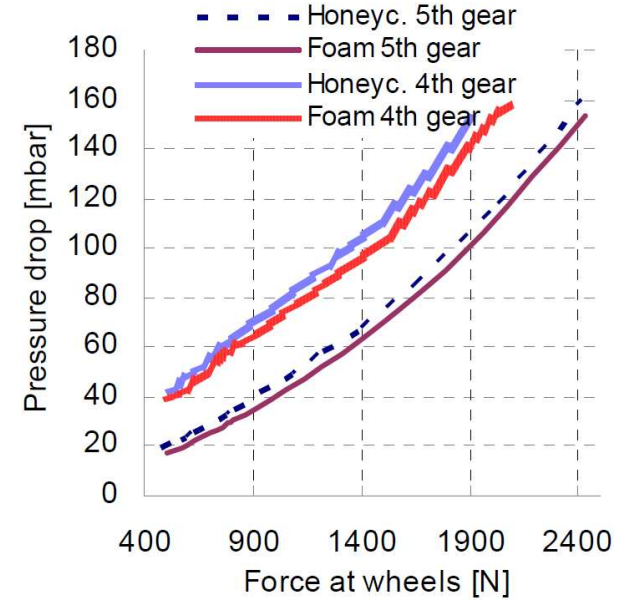

Figure 6. Pressure drop comparison (honeycomb vs. foam)

Although a higher pressure drop and thus a deteriorating effect on the fuel consumption is expected in combination with the foams, $[\underline{10}, \underline{13}]$, the relative high exhaust duct cross section and the associated low flow velocities in combination with the smaller foam dimensions overcompensate a possible specific higher flow resistance. Fig. 7 shows the specific fuel consumption of the engine. As can be expected based on the almost identical pressure drop, Fig. 6, and the operating conditions, Fig. 3 , there are no significant fuel consumption differences. Identical results in respect to pressure drop and fuel consumption have been obtained also with Foam 2.

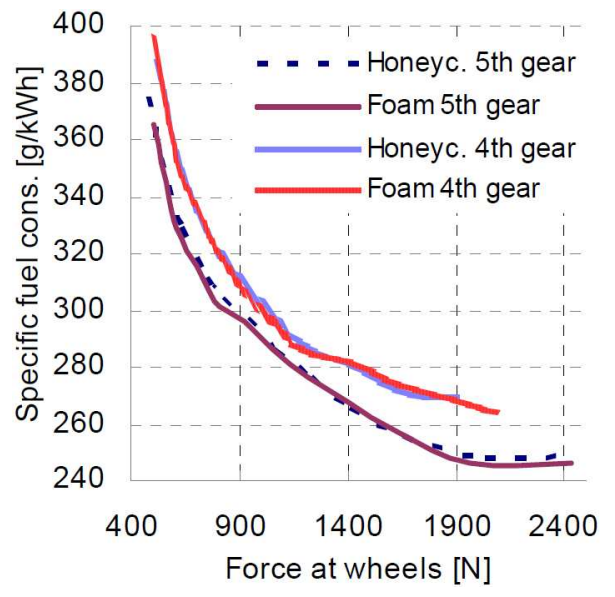

Figure 7. Substrate influence on the specific fuel consumption of the engine (honeycomb vs. foam)

The homogenization effect of the ceramic foams on the flow field was addressed in detail by us in [13]. The question concerning thermal homogenization of the exhaust is addressed by Figs 8 and $\underline{9}$. The plots show the standard deviation of the exhaust temperature among the three thermocouples (at different radial positions) in the measurement plane downstream the DOC, $\underline{\text { Fig. } 8}$ and downstream the DPF, Fig 9. For these investigations a DPF was build in the system, in order also to assess the thermal homogenization impact of the foam DOC downstream the (conventional honeycomb) DPF.

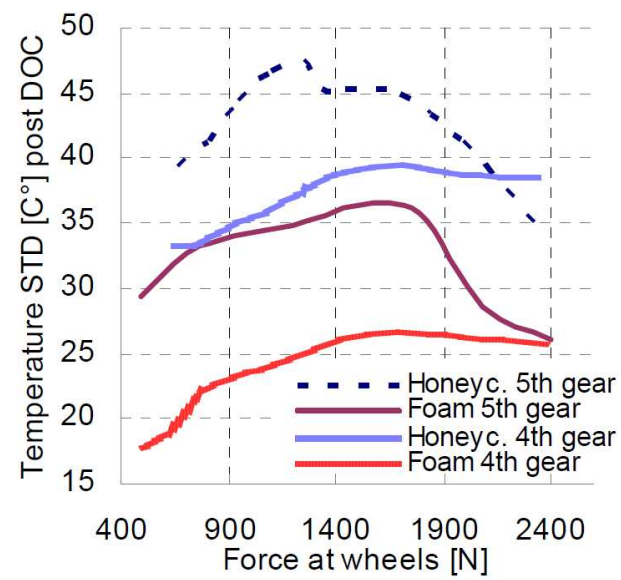

Figure 8. Exhaust temperature standard deviation among the three thermocouples in the measurement plane $B$

The thermal homogenization impact of the foam-DOC on the exhaust gases is stronger than the one of the honeycombs, Fig. 8. Inhomogeneity is reduced by at least $10^{\circ} \mathrm{C}$ with the foams in all compared engine operating points. This is not only the fact for the flow downstream DOC. The DPF seems not to have any strong, additional homogenization impact on the flow as shown in Fig. 9. In contrary, the flow downstream DPF (in combination with the upstream honeycomb DOC) exhibits slightly increased (thermal) inhomogeneity in respect to the inhomogeneity upstream DPF.

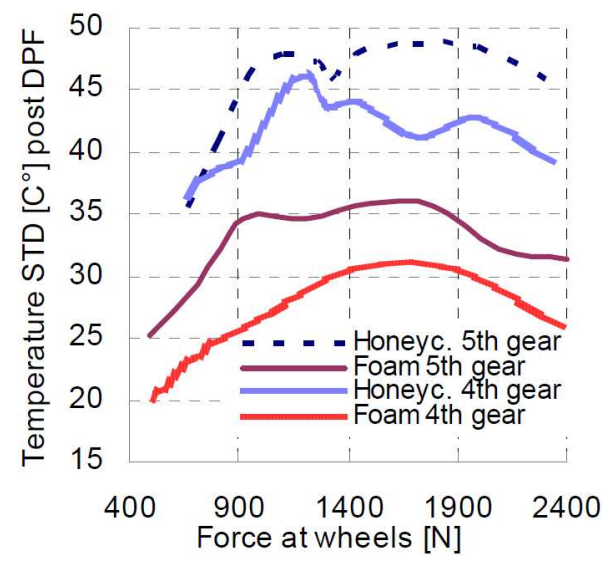

Figure 9. Exhaust temperature standard deviation among the three thermocouples in the measurement plane $C$

The comparisons of the DOCs in terms of pollutant conversion require an additional parameter to be taken into account. Since the dimensions and thus the volume of the 
compared catalysts have not been identical (Table 1), identical exhaust flows are associated with different Gas Hourly Space Velocities (GHSV) through the catalysts. Fig $\underline{10}$ provides an overview of the associated GHSVs at the investigated engine loads.

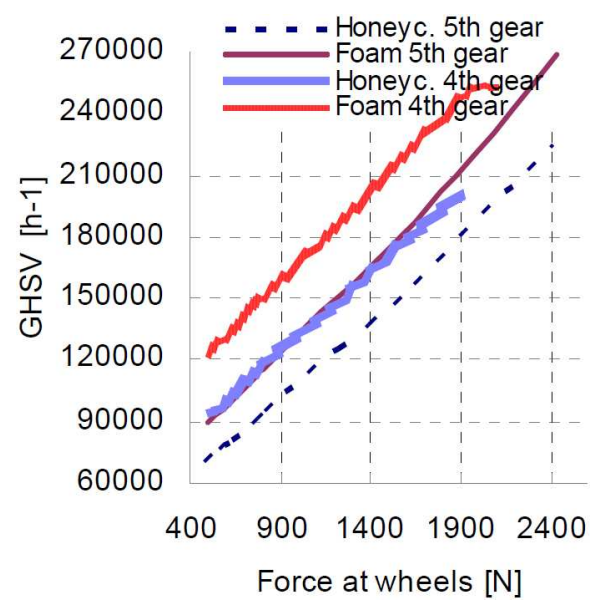

Figure 10. Gas Hourly Space Velocities through the compared catalysts

\section{COMPARISON OF THE HONEYCOMB WITH FOAM 1 IN TERMS OF CONVERSION EFFICIENCY}

The main characteristics of the compared catalysts are listed in Table 1, while the gas hourly space velocities (GHSV) reached during the experiments are summarized in Fig. 10. The engine-out emissions (=pre DOC) have been almost exactly equal for all discussed cases. The comparison in terms of reactivity was considered as more straightforward if plotted over the exhaust temperatures. The relation among the exhaust temperatures and the engine load is given in Fig. 4.

The comparison in terms of $\mathrm{CO}$ oxidation efficiency is shown in Fig. 11. The difference between the honeycomb and the foams are small, especially for the engine operating points associated with the $5^{\text {th }}$ gear, i.e. the lower gas hourly space velocities. Generally the oxidation performance of the foam is satisfactory given the fact that the foam has a third of the Pt amount and approx. three quarters of the volume in respect to the honeycomb. Nevertheless, the significantly higher gas hourly space velocities associated with the engine operation points in combination with the $4^{\text {th }}$ gear result in some additional loss in conversion efficiency for the foam. However the differences remain small, since all conversion efficiencies lie over $94 \%$. Comparing the conversion efficiencies of the foam in combination with engine operating points with the $5^{\text {th }}$ gear and the corresponding ones of the honeycomb in combination with the $4^{\text {th }}$ gear, i.e. comparison at almost identical gas hourly space velocities, the foam conversion efficiency disadvantage is always below $2 \%$.

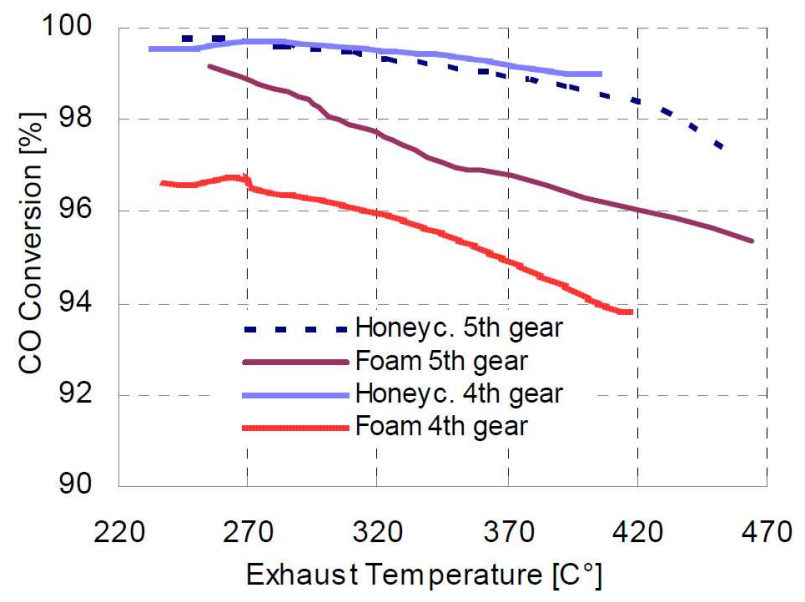

Figure 11. CO oxidation efficiency (honeycomb vs. foam)

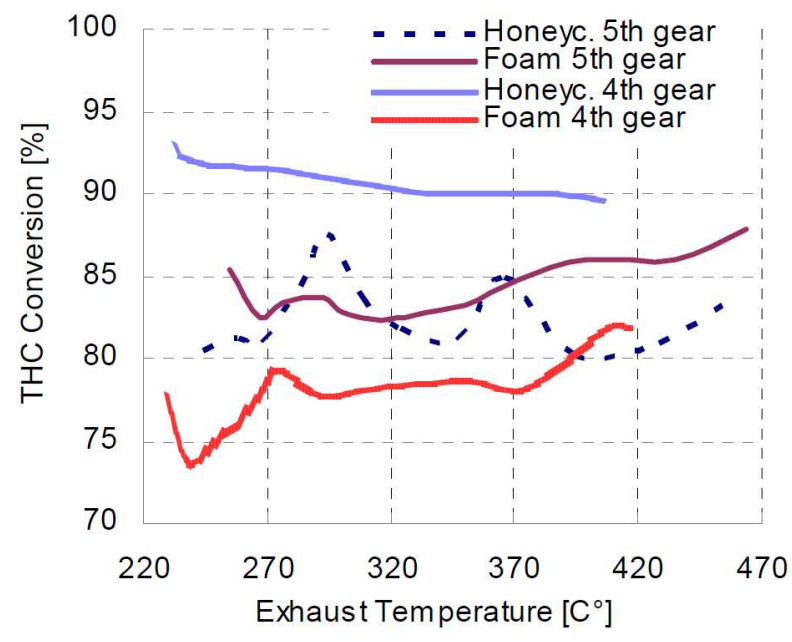

Figure 12. Total unburnt hydrocarbons (THC) oxidation efficiency (honeycomb vs. foam)

Very similar are the results concerning the oxidation of total unbunrnt hydrocarbons (THCs), as shown in Fig. 12. The conversion efficiency of the foam at the engine operating points associated with the 5 th gear is practically equal (if not slightly better) with the corresponding one of the honeycomb. At higher space velocities $\left(4^{\text {th }}\right.$ gear) the foam conversion efficiencies are somehow 5\% lower in respect to the foam conversion efficiencies at the higher gear. Surprisingly, the conversion efficiency of the honeycomb at the engine operating points associated with the $4^{\text {th }}$ gear is the highest, this seems to be a consequence of the different THC concentrations in the exhaust gas upstream the DOC. Nevertheless, all THC oxidation efficiencies are lower than the $\mathrm{CO}$ oxidation efficiencies (comparison of Figs 11 and $\underline{12}$ ). This is not surprising, [20] shows how $\mathrm{CO}$ occupies the 
catalyst first and only after a significant $\mathrm{CO}$ amount is oxidized, hydrocarbon oxidation initiates.

The stronger pronounced conversion decrease with increasing GHSV, as seen when comparing the foams at the two different gears is due to the smaller catalyst dimensions and to the corollary lower available surface area for the reactions. In a previous study [14] we have demonstrated, using numerical simulation, that the foams are characterized by much higher mass transfer ratios from the bulk flow to the catalyst surface in respect to honeycombs. We have though pointed out that this advantage may be partly but also even completely offset by the lower available surface area for the chemical reactions.

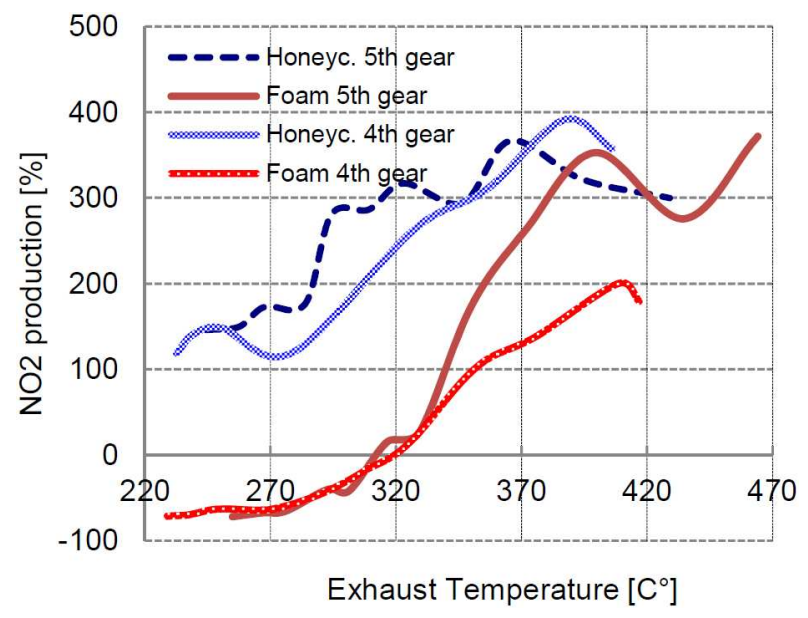

Figure 13. $\mathrm{NO}_{2}$ production efficiency (honeycomb vs. foam)

Apart from the oxidation of $\mathrm{CO}$ and THCs the DOC should oxidize $\mathrm{NO}$ in order to produce $\mathrm{NO}_{2} \cdot \mathrm{NO}_{2}$ is significantly more reactive than $\mathrm{NO}$ and reacts with soot stored in the downstream located DPF. This mechanism is the so-called passive regeneration of the DPF. Thus a high $\mathrm{NO}_{2}$ production in the DOC is a major requirement. Fig. 13 shows a comparison of the honeycomb vs. the foam catalyst.

The same conversion rate definition is kept; i.e. the relation of the amounts of the species in question (here $\mathrm{NO}_{2}$ ) upstream the DOC to the amount downstream the DOC. Thus, values over $100 \%$ are possible in regard to $\mathrm{NO}_{2} ; \mathrm{NO}_{2}$ is generated by the oxidation of the much more abundant $\mathrm{NO}$ (NO engine-out values vary from approx. $100 \mathrm{ppm}$ at low exhaust temperatures to over $700 \mathrm{ppm}$ at the high exhaust temperatures, $\mathrm{NO}_{2}$ engine-out levels lie between 10 and $30 \mathrm{ppm})$.
Before commenting on the Fig. 13, a notion concerning the engine-out $\mathrm{NO}_{2}$ levels is necessary. As already mentioned, most of the engine-out $\mathrm{NO}_{\mathrm{x}}$ is comprised of $\mathrm{NO}$, while $\mathrm{NO}_{2}$ is very low. Thus some measurement inaccuracy should be taken in account. However, the engine-out $\mathrm{NO}_{2}$ concentration measurements have been reproducible regardless of the catalyst in the downstream.

In Fig. 13 the difference of the two catalyst systems in low exhaust temperatures is evident. While the honeycomb seems to have the $\mathrm{NO}_{2}$ related light-off at around $220^{\circ} \mathrm{C}$ the foam catalyst reaches light off at $320^{\circ}$. Below approx. $320^{\circ} \mathrm{C}$ the foams even decrease the engine-out $\mathrm{NO}_{2}$ (most probably reducing it to $\mathrm{NO},[\underline{3}, \underline{21}])$. The $\mathrm{NO}_{2}$ production increases sharply with the increasing exhaust temperature. After $370^{\circ} \mathrm{C}$ there are no significant differences between the compared catalyst systems. However, the foam catalyst limits with increasing GHSV (engine operating points with the $4^{\text {th }}$ gear) are also evident in respect to $\mathrm{NO}_{2}$.

The significant difference concerning the $\mathrm{NO}_{2}$ light-off behavior has been attributed by the catalyst coater to different wash-coat compositions. Unfortunately no further (apart from Table 1) coating composition details can be disclosed either for the honeycomb serial catalyst, or for the foam research catalyst. Nevertheless a different wash-coat composition is expected to reduce significantly the light-off $\mathrm{NO}_{2}$ related disadvantage.

A further question concerns the behavior of the compared DOCs in respect to particle oxidation. It is known that the

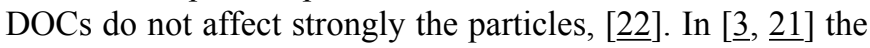
abilities of ceramic foams in oxidizing particles were demonstrated. In Fig. 14 we present a comparison of the particle decrease over the compared catalysts. The comparisons are based on the coincident measurements of the particle number up- and downstream of the DOC. Based on these results it is expected that the DOC is oxidizing the soluble organic fraction of the particles and is only slightly affecting the soot.

The foam based DOC is superior in all the examined cases. The particle number reduction is almost double as high as those achieved by the honeycomb. 


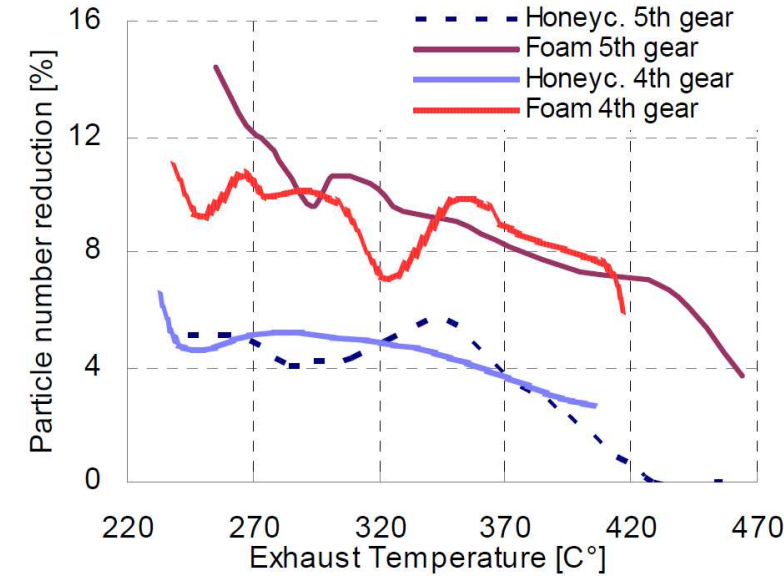

Figure 14. Particle number reduction over the DOCs in comparison (honeycomb vs. foam)

\section{COMPARISON OF THE TWO FOAMS WITH DIFFERENT COATINGS}

The second foam based catalyst was prepared as a possible alternative leading to higher pollutant conversions with even smaller overall dimensions. In order to achieve similar conversions with a smaller catalyst, the $\mathrm{Pt}$ amount in the wash coat was increased. The main data of the second foam catalyst are also summarized in Table 1.

In respect to the original honeycomb, Foam 2 had half of the volume. This resulted in 4 times lower surface available for reactions. On the other hand, the Pt amount on Foam 2 was almost exactly the half of the amount as on the original honeycomb. Foam 2 in comparison to foam 1 had $75 \%$ of the volume. Both foam catalysts were based on the same foam structure, both had the same specific surface area and thus the available surface for reactions in foam 2 was $75 \%$ of the surface in foam 1 . The Pt amount in foam 2 though was $4.33 \mathrm{~g}$ vs. only $2.89 \mathrm{~g}$ on the foam 1 .

As can be seen in the following discussion, the conversion performance of foam 2 was substantially lower than anticipated. The results though, offer interesting insights and lead to important inferences for an optimized design of the wash coat of a foam based catalyst. Fig. 15 presents a comparison of the $\mathrm{CO}$ oxidation performance of the two foam based catalysts, while Fig. 16 presents the comparison concerning the THC oxidation. The results are very similar. Foam 2 is always inferior to Foam 1 in terms of conversion efficiency. The higher space velocities, a direct inference of the smaller dimensions of Foam 2, are detrimental for the conversion and it is obvious that the higher Pt loading of Foam 2 is not capable of counteracting this trend.

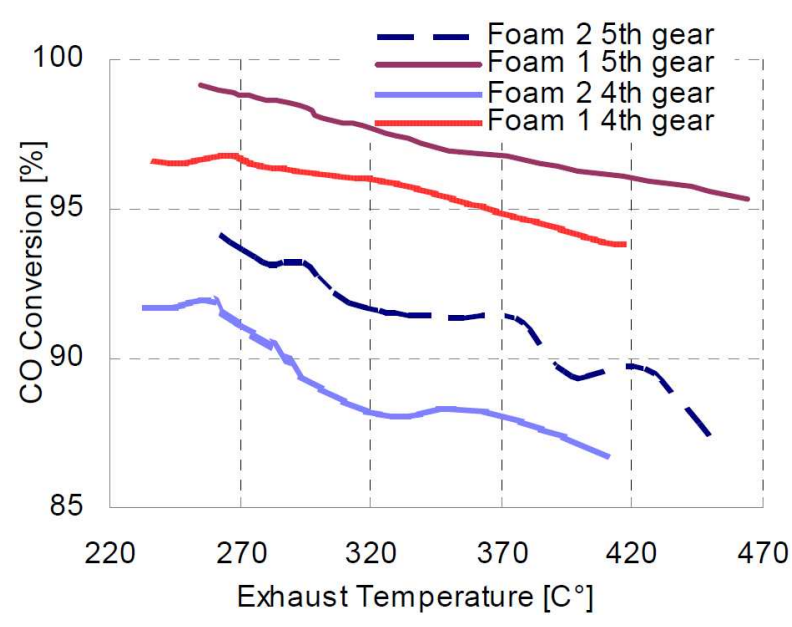

Figure 15. CO oxidation efficiency, comparison of two foam based catalysts

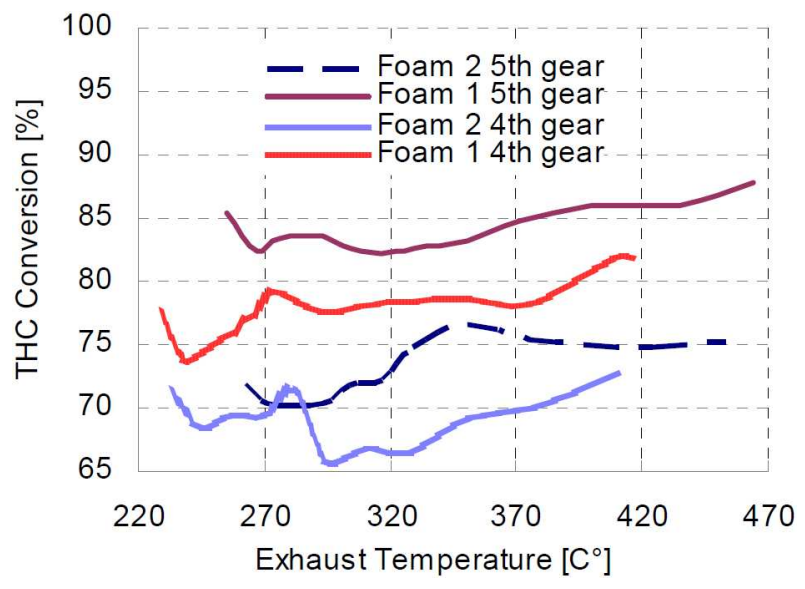

Figure 16. THC oxidation efficiency, comparison of two foam based catalysts

Similar is the behavior of both foam based catalyst systems in respect to $\mathrm{NO}_{2}$ production, as documented by Fig. 17 .

Finally both foams had very similar impact on the particle oxidation. It seems that particle oxidation was not sensitive, neither to the Pt loading, nor to the space velocity and thus to the catalyst dimensions (at least at the catalyst dimensions involved in this study). 


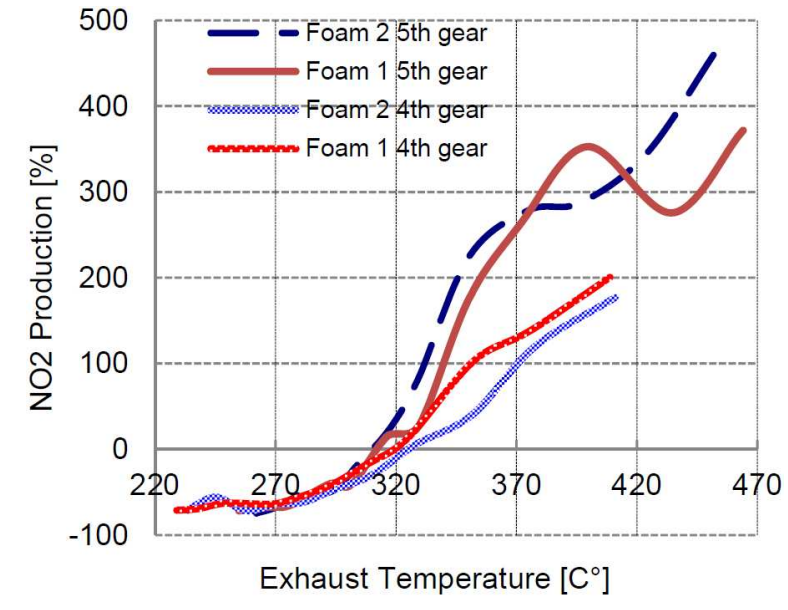

Figure 17. $\mathrm{NO}_{2}$ production efficiency, comparison of two foam based catalysts

In general, the higher Pt amount on Foam 2 does not seem to have a significant influence on the conversion. In addition, it should be taken into account that the average wash coat thickness on the Foam 2 was nearly double as high as in Foam 1. The most appropriate comparison though, would be if the Foam 2 would be available with (at least) two Pt load levels and two wash coat thickness levels.

Nevertheless, the results show that a foam based DOC has the potential to have equal conversion performance as a honeycomb with substantially less Pt. Higher surface areas can be achieved by more dense foams and some increase in dimensions can be achieved without increasing flow resistance at prohibitive levels.

\section{SUMMARY/CONCLUSIONS}

In this study the potential of ceramic foams as substrates for DOCs could be demonstrated.

The tested catalysts have stronger thermal homogenization impact on the exhaust flow,

- in the downstream of the catalyst as well as downstream a subsequent DPF,

- without higher flow resistance and pressure drop,

in respect to the serial production honeycomb.

Further, the conversion efficiency of the foam based catalysts has been compared to the conversion efficiency of the serial production honeycomb catalyst. A $30 \%$ smaller foam catalyst with approx. a third of the Pt amount in respect to the serial honeycomb had

- similar CO and total unburnt hydrocarbons (THC) oxidation performance

- similar $\mathrm{NO}_{2}$ production efficiency at high exhaust temperatures
- substantially higher particulate oxidation performance

With increasing exhaust gas flow and thus increasing gas hourly space velocities the performance of the foam catalyst deteriorated, pointing to additional development requirements. The performance deterioration of the honeycomb with increasing exhaust flow was, if any, substantially lower. Additional $\mathrm{Pt}$ did not improve performance, so that further development will concentrate on improving the foam structure as well as the coating. Foams with higher density for increasing the surface available for chemical reactions as well as modest increase in catalyst dimensions are a very promising path.

Differences in light-off (concerning the $\mathrm{NO}_{2}$ production) as well as between the tested foam catalysts with different coatings underline the necessity for a foam specific wash coat formulation.

\section{REFERENCES}

1. Koltsakis, G., Katsaounis, D., Samaras, Z., Naumann, D. et al., "Development of Metal Foam Based Aftertreatment System on a Diesel Passenger Car," SAE Technical Paper 2008-01-0619, 2008, doi:10.4271/2008-01-0619.

2. Hossfeld, C., Ranalli, M., Katalysatorkonzept zur Reduzierung des Dieselpartikelfilter Volumens, MTZ 67 628-635, 2006

3. Setiabudi, A., Makkee, M., Moulijn, J. A., An optimal usage of NOx in a combined Pt/ceramic foam and a wall-flow monolith filter for an effective NOx-assisted soot oxidation, Topics in Catalysis Vols. 30/31, 2004

4. Dimopoulos, P., Bach, C., Ceramic Foams for Automotive Catalyst Substrate Applications, EET-2008 European EleDrive Conference, International Advanced Mobility Forum, Geneva, Switzerland, 2008

5. Dimopoulos, P., Thurnheer, T., Bach, C., High efficiency exhaust aftertreatment: Purposeful application of ceramic foams, MTZ-Konferenz, "Der Antrieb von morgen", Proceedings, München, 2008

6. Chakravarthy, V.K., Conklin, J.C., Daw, C.S, Azevedo EF, E.F., Multi-dimensional simulations of cold-start transients in a catalytic converter under steady inflow conditions, Appl Catal A 241: 289-306, 2003

7. Gaiser, G., Oesterle, J., Braun, J., and Zacke, P., “The Progressive Spin Inlet - Homogeneous Flow Distributions Under Stringent Conditions," SAE Technical Paper 2003-01-0840, 2003, doi:10.4271/2003-01-0840.

8. Ranalli, M., Hossfeld, C., Kaiser, R., Schmidt, S. et al., "Soot Loading Distribution as a Key Factor for a Reliable DPF System: An Innovative Development Methodology," SAE Technical Paper 2002-01-2158, 2002, doi: 10.4271/2002-01-2158. 
9. Oesterle, J., Gaiser, G., and Zacke, P., "Homogeneous Loading and Regeneration of Diesel Particulate Filters using Progressive Spin Elements," SAE Technical Paper 2004-01-1424, 2004, doi:10.4271/2004-01-1424.

10. Giani, L., Groppi, G., Tronconi E, E., Mass-Transfer Characterization of Metallic Foams as Supports for Structured Catalysts. Ind Eng Chem Res 44: 4993-5002, 2005

11. Vogt, U. F., Wagner, G., Broenstrup, A., Eggenschwiler, P. Dimopoulos, Gorbar, M., Colombo, P., Improving the Properties of Ceramic Foams by a Vacuum Infiltration Process, Journal of the European Ceramic Society, J. Eur. Ceram. Soc. doi:10.1016/j.jeurceramsoc.2010.06.003, 2010

12. Dimopoulos, P., Bach, C., Vogt, U., and Herrmann, K., "Ceramic Foams as Catalyst Substrates: Pre-catalyst Application Homogenising the Exhaust Flow upstream of Aftertreatment Devices," SAE Technical Paper 2007-24-0097, 2007, doi:10.4271/2007-24-0097.

13. Eggenschwiler, P. Dimopoulos, Tsinoglou, D. N., Seyfert, J., Bach, C., Vogt, U. F., Gorbar, M., Ceramic foam substrates for automotive catalyst applications. Fluid mechanic analysis, Experiments in Fluids, Springer Verlag Berlin/Heidelberg, 47, 2, 209-222, 2009

14. Tsiniglou, D. N., Eggenschwiler, P. Dimopoulos, Thurnheer, T., Hofer, P., A simplified model for natural-gas vehicle catalysts with honeycomb and foam substrates, Proc. IMechE, Vol. 223 Part D: J. Automotive Engineering, 819-834, 2009

15. Schreiber, D., Forss, A., Mohr, M., and Dimopoulos, P., "Particle Characterisation of Modern CNG, Gasoline and Diesel Passenger Cars," SAE Technical Paper 2007-24-0123,2007, doi:10.4271/2007-24-0123.

16. Garrido, G. Incera, Patkas, F.C., Lang, S., KraushaarCzarnetzki B, B., Mass transfer and pressure drop in ceramic foams: A description for different pore sizes and porosities, doi:10.1016/j.ces.2008.06.015, 2008

17. Twigg, M., Richardson, J., Theory and Applications of Ceramic Foam Catalysts. Chem Eng Res Des 80(2): 183-189, 2002

18. Habisreuther, P., Djordjevic, N., Zarzalis, N., Numerische Simulation der Mikroströmung in prösen inerten Strukturen, Chemie Ingenieur Technik, 80, 3, 327-341, 2008

19. Hayes, R., Kolaczkowski, S. T., Li, P. K. C., Audry, S., Evaluating the effective diffusivity of methane in the wash coat of honeycomb monolith, Appl. Catalysis, B, 25(2-3), 93-104, 2000

20. Peck, R. S., Experimentelle Untersuchung und dynamische Simulation von Oxidationskatalysatoren und Diesel-Partikelfiltern, PhD Thesis, Universitaet Stuttgart, 2006

21. Setiabudi, A., Makkee, M., Moulijn, J. A., An optimal NOx assisted abatement of diesel soot in an advanced catalytic filter design, Applied Catalysis B: Environmental 42, 35-45, 2003

22. Basshuysen, R.v, Schäfer, F., Handbuch

Verbrennungsmotoren, Vieweg, 2nd edition, 2002

\section{CONTACT INFORMATION}

P. Dimopoulos Eggenschwiler, Dr. sc. techn.

Leiter/Head Gruppe Abgasnachbehandlung/

Exhaustaftertreatment Group

Internal Combustion Engines Laboratory Empa Swiss Federal

Laboratories for Materials Science and Technology

Ueberlandstrasse $129 \mathrm{CH}-8600$ Duebendorf

Tel +41-58-765 4337

Fax +41-58-765 4041

panayotis.dimopoulos@empa.ch

www.empa.ch

\section{LIST OF ABBREVIATIONS}

\section{CLD}

Chemiluminessence Detector

CPC

Condensation Particle Counter

DOC

Diesel Oxidation Catalyst

DPF

Diesel Particulate Filter

ECU

Electronic Control Unit (of engine)

FID

Flame Ionization Detector

GHSV

Gas Hourly Space Velocity

NDIR

Non Dispersive Infra Red Detector

PGM

Platin Group Metals

SEM

Scanning Electron Microscope 
THC

Total unburnt HydroCarbons

\section{TWC}

Three way Catalyst

\section{ACKNOWLEDGMENTS}

Support for this project was granted by:

- Competence Center Energy and Mobility (CCEM) of the Paul Scherrer Institute, Switzerland,

- Fiat Powertrain Technologies, Iveco Motorenforschung AG, Arbon, Switzerland

- Umicore Automotive Catalysts AG, Hanau-Wolfgang, Germany.

The authors express their gratitude to these institutions as well as to the involved persons.

The Engineering Meetings Board has approved this paper for publication. It has successfully completed SAE's peer review process under the supervision of the session organizer. This process requires a minimum of three (3) reviews by industry experts.

All rights reserved. No part of this publication may be reproduced, stored in a retrieval system, or transmitted, in any form or by any means, electronic, mechanical, photocopying, recording, or otherwise, without the prior written permission of SAE. ISSN 0148-7191
Positions and opinions advanced in this paper are those of the author(s) and not necessarily those of SAE. The author is solely responsible for the content of the paper.

SAE Customer Service:

Tel: 877-606-7323 (inside USA and Canada)

Tel: 724-776-4970 (outside USA)

Fax: 724-776-0790

Email: CustomerService@sae.org

SAE Web Address: http://www.sae.org

Printed in USA 